\title{
Toppling Analysis of the Echo Cliffs Precariously Balanced Rock
}

\author{
by Swetha Veeraraghavan, Kenneth W. Hudnut, and Swaminathan Krishnan
}

\begin{abstract}
Toppling analysis of a precariously balanced rock (PBR) can provide insight into the nature of ground motion that has not occurred at that location in the past and, by extension, can constrain peak ground motions for use in engineering design. Earlier approaches have targeted 2D models of the rock or modeled the rockpedestal contact using spring-damper assemblies that require recalibration for each rock. Here, a method to model PBRs in 3D is presented through a case study of the Echo Cliffs PBR. The 3D model is created from a point cloud of the rock, the pedestal, and their interface, obtained using terrestrial laser scanning. The dynamic response of the model under earthquake excitation is simulated using a rigid-body dynamics algorithm. The veracity of this approach is demonstrated through comparisons against data from shake-table experiments. Fragility maps for toppling probability of the Echo Cliffs PBR as a function of various ground-motion parameters, rock-pedestal interface friction coefficient, and excitation direction are presented. These fragility maps indicate that the toppling probability of this rock is low (less than 0.2 ) for peak ground acceleration (PGA) and peak ground velocity (PGV) lower than $3 \mathrm{~m} / \mathrm{s}^{2}$ and $0.75 \mathrm{~m} / \mathrm{s}$, respectively, suggesting that the ground-motion intensities at this location from earthquakes on nearby faults have most probably not exceeded the above-mentioned PGA and PGV during the age of the PBR. Additionally, the fragility maps generated from this methodology can also be directly coupled with existing probabilistic frameworks to obtain direct constraints on unexceeded ground motion at a PBR's location.
\end{abstract}

Electronic Supplement: Text and figures describing the steps involved in the modeling of precariously balanced rock (PBR)-pedestal geometry, including dense point cloud representation and final 3D model, hazard deaggregation, and toppling probability.

\section{Introduction}

Critical facilities such as nuclear power plants or nuclear waste repositories must be protected against earthquake damage by designing them to withstand intense ground shaking from very low probability earthquakes $\left(10^{-4} / \mathrm{yr}\right.$ to $\left.10^{-9} / \mathrm{yr}\right)$ on regional faults. The standard probabilistic seismic-hazard analysis (PSHA) procedures predict very high ground-motion amplitudes for these low-probability events. For example, the 1998 Yucca Mountain project PSHA predicted a peak ground acceleration (PGA) of $107.8 \mathrm{~m} / \mathrm{s}^{2}$ and peak ground velocity (PGV) of $13 \mathrm{~m} / \mathrm{s}$ at a mean hazard level of $10^{-8} / \mathrm{yr}$ (Stepp et al., 2001). Designing critical facilities for these extreme ground motions, which are much higher than the maximum recorded ground motion, is very challenging and expensive. Andrews et al. (2007) suggested that these high-PGV values might be physically unrealizable at the Yucca Mountain site because the rock at this site might not have sufficient shear strength to propagate horizontal PGVs higher than $3.6 \mathrm{~m} / \mathrm{s}$.
In the absence of recorded ground motion extending far into the past, Brune and Whitney (1992) and Brune (1996) showed that the hazard derived from the standard PSHA procedures can be supplemented or constrained using sensitive geological features. Geological features such as precariously balanced rocks (PBRs) have existed in their present precarious conditions for thousands of years. The presence of a PBR in a region provides evidence that earthquake shaking strong enough to topple it has not occurred there during the rock's existence in that precarious condition. Therefore, the critical toppling intensity of a PBR in conjunction with its age may provide an independent constraint on unexceeded ground motion at a location as shown by Purvance, Brune et al. (2008), Baker et al. (2013) and Hanks et al. (2013). Anderson et al. (2014) present an overview of how PBRs can be used to place upper limits on ground shaking at that location. 
Brune and his colleagues conducted road surveys near major fault zones and cataloged hundreds of PBRs in southern California and Nevada (Brune, 1996). Most of these PBRs have evolved naturally through weathering of a buried rock mass into corestones, followed by erosion of the overlying surface materials (Linton, 1955) or are a by-product of a weathering-induced tread-and-riser hillslope morphology. PBRs thus formed are generally not still connected to their pedestals (Bell et al., 1998). Bell et al. (1998) analyzed several PBRs in southern California using the varnish micro-lamination method and concluded that they have been present in precarious configuration for at least 10,500 radiocarbon years, that is, $\sim 12,000$ calendar years, without significant alteration in their present shape.

The focus in this article is on estimating the critical toppling intensity of the PBRs as represented by various measures that characterize ground-motion amplitude, frequency content, and duration. Most of the earlier works in this area are closely related to the response of rigid rectangular objects to earthquake excitation. The equation of motion for the rocking response of a rectangular object subjected to horizontal ground excitation has been analyzed for almost a century. This equation of motion is nonlinear and nonsmooth requiring numerical solution or linearization to evaluate the response. The linearized equation of motion for the rocking response of the rectangular object under simple base excitation such as a sinusoidal pulse has been analytically solved by many authors (Kirkpatrick, 1927; Kimura and Iida, 1934a,b; Ikegami and Kishinouye, 1947, 1950; Housner, 1963). Yim et al. (1980) numerically solved the linearized equations of motion for the rocking response of a rectangular object subjected to ensembles of ground excitations. In the years that followed, several researchers continued studying the nonlinear equations of motion for the rocking, sliding, and coupled rocking-sliding response of such objects using both analytical as well as numerical methods (Ishiyama, 1982; Shi et al., 1996; Zhang and Makris, 2001; Taniguchi and Miwa, 2007; Voyagaki et al., 2012, 2014)

Purvance, Anooshehpoor, and Brune (2008) were the first to apply the rigid-body rocking dynamics framework to the PBR problem. Following the Yim et al. (1980) approach, they numerically simulated the rocking and toppling response of symmetric and asymmetric $2 \mathrm{D}$ objects under synthetically generated random vibration excitations under the assumption that the $2 \mathrm{D}$ object comes in contact with the ground at only two points and can rock only about those two points (henceforth referred to as two-point contact). They used the results from this numerical analysis to develop an empirical expression for estimating the toppling probability of a $2 \mathrm{D}$ object as a function of its geometric parameters and various ground-motion intensity measures such as PGA, the ratio of PGV to PGA (PGV/PGA), and spectral acceleration at $1 \mathrm{~s}\left(\mathrm{SA}^{1 \mathrm{~s}}\right)$ and $2 \mathrm{~s}\left(\mathrm{SA}^{2 \mathrm{~s}}\right)$. This empirical equation accurately predicted the PGA required to topple blocks, formed by extruding a $2 \mathrm{D}$ vertical cross section (e.g., a cuboid), in a shake-table experiment. However, it overpredicted the PGA required to topple rocks. It does not account for the 3D form of the rock or the curved form of basal contact (with multiple contact points) and predicts greater stability for the rock than what is observed in the experiments. To correct for the multiple contact points, Purvance, Anooshehpoor, and Brune (2008) conducted tilt tests on the rock (Anooshehpoor et al., 2004) by quasi-statically tilting the rock until it is just about to topple and measured the minimum force as a function of tilt angle required to maintain static equilibrium. Using results from the tilt tests, they adjusted the location of the two sharp corners in the 2D model based on the ratio of the maximum force recorded in tilt test to the weight of the rock. They demonstrated the accuracy of this methodology by comparing the results predicted by the empirical relation with shaketable experiments on three rocks.

The empirical expression (with the contact point correction) still assumes the response of the object to be restricted to the vertical plane along the applied one-component horizontal excitation. Although this is true for a cuboid (3D block with rectangular cross section) under uniaxial ground excitation, for most rocks this may not be true, owing to their 3D geometry and the complex rock-pedestal interface, especially under three-component ground excitation. Moreover, inaccessible locations of most PBRs make it difficult to perform the in situ tilt tests required for the contact point correction. Even where these tilt tests are possible, an unintended consequence of the physical separation of the surfaces during the tests could disturb the rock-pedestal interface and potentially change its behavior during future earthquakes.

To overcome these issues, Purvance et al. (2012) developed Rigid to analyze the response of 3D PBR models to earthquake ground excitation using the discrete element method. They modeled the rock and pedestal as two separate rigid bodies and used the penalty stiffness method, which is analogous to a spring-damper assembly, to model the contact between the rock and the pedestal. They modeled the tangential contact between the rock and pedestal by placing a tangential spring that has a user-defined stiffness until the friction force limit (coefficient of friction $\times$ normal force) is reached. Beyond this limit, the spring stiffness is reduced to zero to simulate slipping. This method tends to emulate Coulomb friction as the user-defined spring stiffness tends to infinity. They modeled the reduction in velocity of the rock upon impact with the pedestal using a hysteretic damping model. However, the coefficient of restitution is not uniquely defined for this hysteretic model.

Although Purvance's model has been tested successfully against shake-table experiments conducted on cuboids, it has not been tested against experiments on real rocks. Furthermore, these studies have been limited to rocking. The capability of the Rigid methodology in simulating sliding and coupled rocking-sliding and bouncing response of a cuboid/PBR has not been validated. The main limitation of this algorithm is that the stiffness and damping values of the spring-dashpot assembly need to be calibrated carefully for each rock in order to obtain realistic simulations while keeping 
(a)

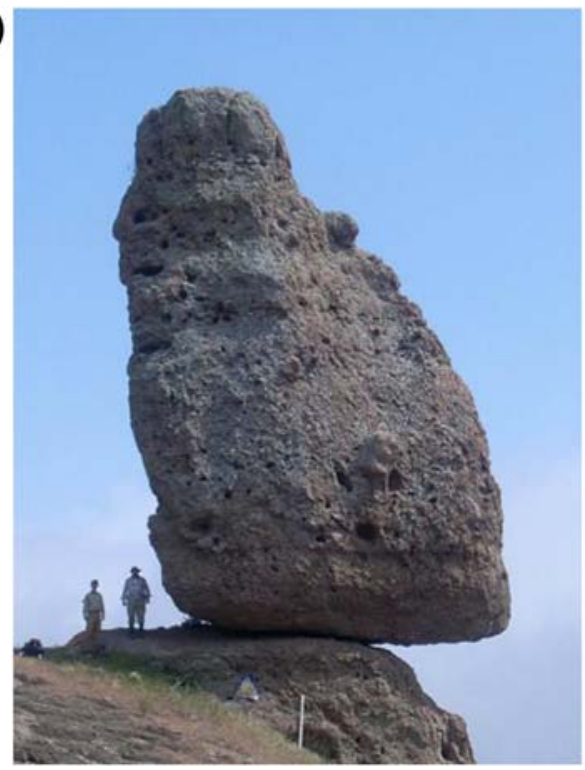

(b)

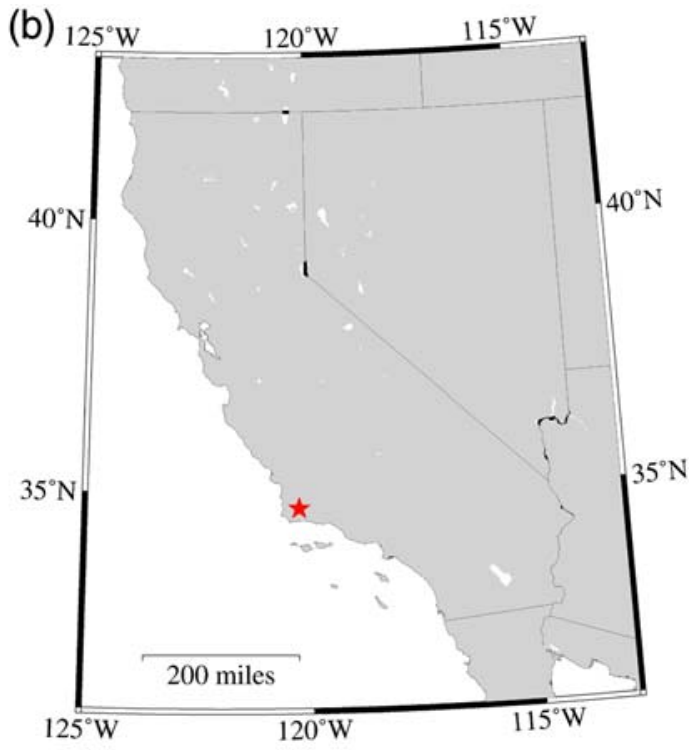

Figure 1. (a) A close-up picture of the Echo Cliffs precariously balanced rock (PBR) that is $\sim 14 \mathrm{~m}$ tall and $8 \mathrm{~m}$ wide and (b) its location (indicated by the star) in the western Santa Monica Mountains (latitude $34.126147^{\circ}$ and longitude $-118.926561^{\circ}$ ). The color version of this figure is available only in the electronic edition.

computational costs manageable, that is, the spring stiffness has to be chosen such that the resulting simulation timestep is not too small but at the same time the overlap (i.e., the common volume shared) between the rock and the pedestal is minimized. The spring stiffness that may be adequate at the start of the simulation might cause unrealistic rock-pedestal overlap during the course of the simulation depending on the ground-motion time history. So even for one rock, it is difficult to arrive at an optimum spring stiffness that will work for a suite of ground-motion time histories.

Here, we present an alternate method to analyze the 3D PBR models using a versatile rigid-body dynamics algorithm that is capable of simulating the rocking and sliding response of arbitrarily shaped objects under earthquake excitation. This algorithm (chapter 2 of Veeraraghavan, 2015, see also Data and Resources) uses a constraint-based method to model the contact between the rock and the pedestal. In this method, a user-defined contact tolerance is used to first determine the points on the rock that are in contact with the pedestal. Then, the contact forces at these points are computed to satisfy nonoverlap constraints between the rock and the pedestal and Coulomb's interface friction law. The contact tolerance, which may be as low as $1 \mathrm{~mm}$ for a rock of $1 \mathrm{~m}$ height, ensures that the degree of penetration of the pedestal by no point on the rock exceeds this value.

The difference between the penalty stiffness (Rigid) and constraint-based (our algorithm) methods for modeling normal contact (perpendicular to the pedestal surface) can be illustrated by considering a cube that is quasi-statically placed on a table and is in contact with the table at the four corners. In the absence of the table, the vertical acceleration at each of the four corners would be $-g$. In the constraintbased method, a contact force of $m g / 4$ is applied at each corner, and the weight of the cube $-m g$ is balanced. The magnitude of the calculated contact force is independent of the user-specified contact tolerance. On the other hand, in the penalty stiffness method, the cube penetrates into the table for one timestep, resulting in a penetration $(\delta)$. The resulting contact force at each corner is $k \delta$, in which $k$ is the contact stiffness. These contact forces may not exactly balance the weight of the cube. In cases for which a high contact stiffness is chosen, the resulting contact force may be higher than the weight of the cube and might cause the cube to lose contact with the table and to oscillate on the table for many timesteps before coming to rest.

The advantage of using constraint-based contact over Rigid for modeling the response of the $3 \mathrm{D}$ PBR model is that (1) the overlap between the PBR and pedestal cannot exceed the user-specified value; (2) there are no springs/ dashpot systems in the simulation whose values have to be calibrated; (3) frictional contact obeys Coulomb's friction laws; and (4) energy dissipation upon impact is modeled using Newton's laws of collision (using the coefficient of restitution). The solution given by our algorithm matches the solution obtained by solving the equations of motion for the rocking response of a rectangular object and for a coupled rocking-sliding response of a rectangular object (Veeraraghavan, 2015). In this article, we further validate the algorithm with results from the Purvance, Anooshehpoor, and Brune (2008) rock-on-shake-table experiments and estimate the ground motions required to topple the Echo Cliffs PBR (Fig. 1), located in the western Santa Monica Mountains. We expect this prototype study to provide an impetus for $3 \mathrm{D}$ modeling and analysis of hundreds of PBRs identified and cataloged by Brune et al. (2006). 


\section{Echo Cliffs PBR}

The Echo Cliffs PBR is a massive rock that is $\sim 14 \mathrm{~m}$ high and $10 \mathrm{~m}$ wide. The rock type is Conejo Volcanic (middle Miocene) conglomerate, identical to that seen in adjacent cliffs, and probably originating as debris flow or lahar deposits (Yerkes et al., 1979). Most PBRs in southern California, on the other hand, happen to be granitic. Its precarious present-day geometry is presumed to have formed by mechanical and chemical weathering and degradation processes in place as the ridge line, of which it is a part, eroded over time. Erosion has produced the "tread and rise" or stair-step geometry of the adjacent hillslope and ridge, progressively exposing this PBR and its pedestal (Hudnut et al., 2009). Differential weathering along a nearly vertical joint plane has exposed the top and sides of the PBR to more rapid erosion, leaving near-vertical and rounded upper surfaces. Currently, there are no other PBRs present in the vicinity of this rock. Either none formed or those that formed have been toppled in past earthquakes.

Brune (1996) classified free-standing rocks as precarious if the quasi-static toppling acceleration, that is, the minimum constant ground acceleration that can topple the rock, is less than $3 \mathrm{~m} / \mathrm{s}^{2}$. Based on this classification, the Echo Cliffs PBR is precarious with quasi-static toppling acceleration varying between 2 and $4 \mathrm{~m} / \mathrm{s}^{2}$, depending on the direction of ground excitation. This directional quasi-static toppling acceleration is calculated by taking a vertical cross section of the Echo Cliffs PBR (passing through its center of gravity) along eight equally spaced horizontal ground excitation directions and by following the methodology detailed in Anooshehpoor et al. (2004). The presence of crushed rock particles near the base of the Echo Cliffs PBR (Hudnut et al., 2009) suggests that rocking motion may have occurred in the past and that any connectivity that may have existed between the PBR and its pedestal may now be severed. Although the PBR is now physically disconnected at its base and is freestanding on its pedestal, it has neither been dislodged nor has it moved significantly from its original location.

This rock has survived many historic earthquakes of magnitude 6.5 and above, such as the 1812 Ventura earthquake $\left(M_{\mathrm{w}} 7.1\right)$, the 1925 Santa Barbara earthquake $\left(M_{\mathrm{w}} 6.8\right)$, the 1927 Lompoc earthquake $\left(M_{\mathrm{w}} 7.1\right)$, more recently the 1971 San Fernando earthquake ( $M_{\mathrm{w}} 6.7$ originating $57 \mathrm{~km}$ from the Echo Cliffs PBR), and the 1994 Northridge earthquake ( $M_{\mathrm{w}} 6.7$ originating $36 \mathrm{~km}$ from the Echo Cliffs PBR). The proximity of this rock to the Los Angeles urban area further amplifies the seismic significance of this PBR. Unfortunately, efforts taken to estimate the age of the rock, by dating this rock and the adjacent cliff using two methods (Chlorine-36 and Helium-3 - attempted by others) have failed to yield reliable results (Hudnut et al., 2009).

\section{Modeling the Echo Cliffs PBR-Pedestal System}

Approximating the PBR and its pedestal as rigid bodies eliminates the need to characterize stiffness-related properties such as Young's modulus, shear modulus, and bulk modulus, and strength-related properties such as fracture toughness and crushing (compressive) strength. Also, the response of a rigid body depends not on the absolute, but on the relative distribution of mass density. If the rock is further assumed homogeneous (i.e., the mass density is uniform), then the dynamic response does not depend on the numerical value of the mass density. The only material-related properties that need to be defined are the coefficients of static friction, kinetic friction, and restitution between the PBR and its pedestal, so that relative sliding and impact may be modeled.

The rigid-body dynamics algorithm assumes the rock and the pedestal to be separate rigid bodies. The pedestal is assumed to have infinite mass and mass moment of inertia, implying that it moves integral to the ground. We further assume that the ground and the pedestal only translate, but do not rotate (i.e., rotational ground motions are not considered). The input to the algorithm includes the coordinates of points describing the surfaces of the pedestal and the rock, the volume, mass moment of inertia (I) and center of mass of the rock, the coefficients of static and kinetic friction at the rock-pedestal interface, and the coefficient of restitution between the rock and pedestal.

Two popular methods for obtaining the rock and pedestal surficial coordinates are photogrammetry and the more recent terrestrial laser scanning (TLS). In the photogrammetry method, pictures taken from different angles are combined to construct the $3 \mathrm{D}$ point cloud describing the geometry of the rock and its pedestal (Purvance et al., 2012). In TLS, a laser scanner, operated from numerous points of view of the rock (from as close as $15 \mathrm{~m}$, and as far away as several hundred meters) is used to obtain an accurate geometric representation of the overall rock-pedestal system. The Echo Cliffs PBR was imaged by Hudnut et al. (2009) using TLS. To include intricate details of the rock-pedestal interface, the interface was scanned from several tripod positions within less than $75 \mathrm{~m}$ distance.

From the dense surficial point cloud obtained from TLS (Fig. 2a), the points belonging to the rock and pedestal are separated by assuming the interface between the rock and the pedestal (Fig. 2b) lie on a planar surface. A 3D void-free polygon is created from the points belonging to the rock using Delaunay triangulation. The physical properties of the rock, such as volume and center of gravity are extracted from this polygon. To model the contact between the rock and the pedestal accurately, the initial contact interface between the rock and the pedestal is modeled by smoothing the dense interface point cloud (Fig. 2b). To model the time-evolving rock-pedestal contact interface, a finely sampled rock surface with a closely spaced set of candidate points, especially near the rock's base, is extracted from the 3D polygon describing the rock. Finally, a piecewise linearly interpolated pedestal surface is constructed from the points that belong to the pedestal (Fig. 2c). More details about modeling the rock-pedestal geometry can be found in the (E) electronic supplement to the article. 
(a)

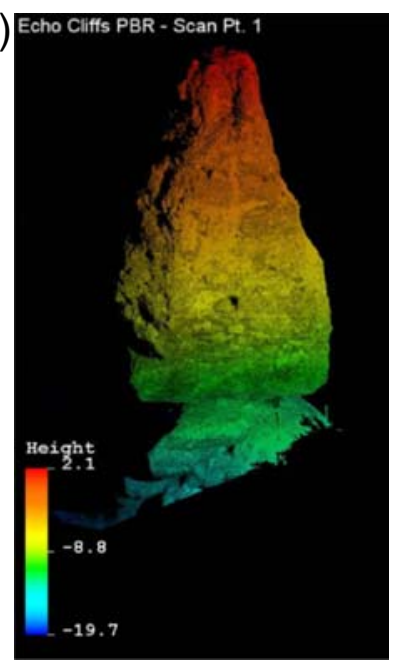

(b)

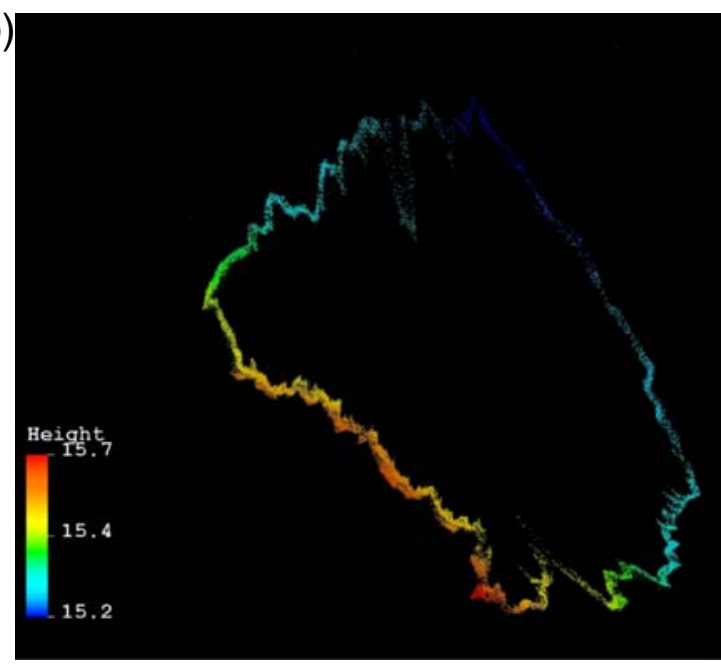

(c)

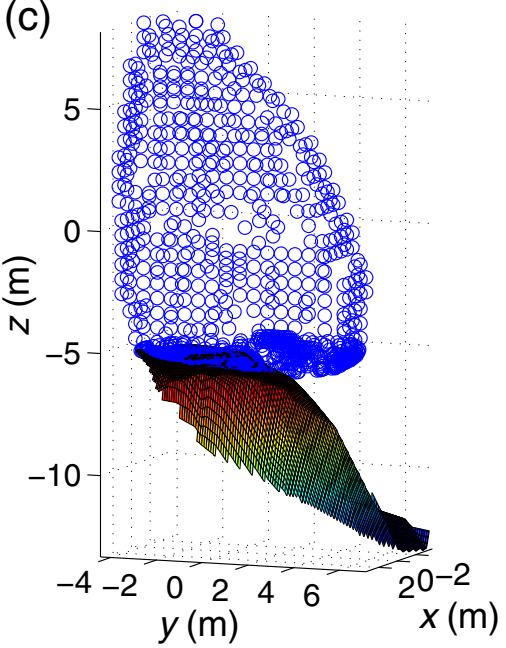

Figure 2. Echo Cliffs PBR. (a) The dense point cloud obtained from terrestrial laser scanning (TLS) techniques. (b) The slice of points that encloses the rock-pedestal interface (dense interface-point cloud). (c) Final 3D model with the pedestal surface and the points representing the outer surface of the rock. The color version of this figure is available only in the electronic edition.

After reviewing results from friction experiments on different rock types subjected to varying normal stresses, Byerlee (1978) inferred that the friction coefficient is independent of rock type/material and varies between 0.6 and 1.0 for rocks under low normal stresses $(<5 \mathrm{MPa})$. The normal stress applied by the Echo Cliffs PBR on its pedestal, that is, weight of the rock divided by contact area, is in the 1-1.5 MPa range based on commonly encountered rock densities of $2000-3000 \mathrm{~kg} / \mathrm{m}^{3}$. Therefore, the static and kinetic friction coefficients between a PBR and its pedestal may be assumed to be in the 0.6-1.0 range.

The rebound velocity of a rigid body upon impact is characterized by the coefficient of restitution. In the shake-table experiments conducted by Purvance, Anooshehpoor, and Brune (2008), the rebound velocity of the rock upon impact with the table was negligible. Therefore, the coefficient of restitution between the PBR and its pedestal is assumed to be zero, resulting in perfectly inelastic rock-to-pedestal collisions.

\section{Validation of the Rigid-Body Dynamics Algorithm}

The rigid-body dynamics algorithm has been validated against the analytical solution of the rocking-slidingimpacting of simple rigid-body assemblies such as a rectangular object on a horizontal surface in chapter 2 of Veeraraghavan (2015). To further validate the accuracy of the algorithm in analyzing real rocks with complex 3D shapes, we use the results from shake-table tests of an actual rock (Fig. 3a) labeled $\mathrm{K}$ in Purvance, Anooshehpoor, and Brune (2008). Starting with multidirectional images of the rock, obtained from M. Purvance (personal comm., 2012), we constructed the 3D point cloud describing the rock and its pedestal (a flat surface in this case) using Insight3D (see Data and Resources; Fig. 3b). The point cloud obtained from Insight3D cannot distinguish between points belonging to the rock and pedestal unless there are high-resolution images near the contact interface and the rock and pedestal are separately marked. In the absence of high-resolution images near the contact interface, the points near the rock-pedestal interface are adjusted to visually match the multidirectional images. Starting with this point cloud, the 3D geometry of the rock (Fig. 3c) is created using the procedure outlined in the earlier section. It is then verified that the slenderness values of the rock match with those provided in Purvance, Anooshehpoor, and Brune (2008) for rock K. The slenderness value here is calculated by taking the vertical cross-section of the rock passing through the rock's center of gravity, along the direction in which the rock is most fragile. Then, the ratio of the lateral extent of the rock's base (horizontal distance between the rock's center of gravity to the farthest point from the center at which the rock is in contact with the ground) to the height of the center of gravity gives the slenderness of the rock.

Purvance, Anooshehpoor, and Brune (2008) subjected rock $\mathrm{K}$ to scaled versions of 10 single-component groundmotion waveforms on the shake table. Of these, two are synthetically generated, and one is a $2-\mathrm{Hz}$ full sine wave. The remaining ground-motion histories are the strong component of recorded ground motion from various earthquakes. The 10 waveforms were first scaled such that their PGA is $0.981 \mathrm{~m} / \mathrm{s}^{2}$. Then, they are scaled up in steps of $0.245 \mathrm{~m} / \mathrm{s}^{2}$ from a PGA of $0.981 \mathrm{~m} / \mathrm{s}^{2}$ to a level at which the rock topples. The peak ground displacement (PGD) of the records was maintained below the $0.3 \mathrm{~m}$ displacement capacity of the shake table by applying a high-pass Butterworth filter to the scaled waveforms. The rock is placed on a roughened concrete slab to preclude sliding. Ground motions are applied in the direction in which the least PGA is required to initiate rocking. The smallest PGA at which the rock topples under the scaled versions of the 10 waveforms is shown plotted (squares) as a function of the waveform PGV/PGA ratio in Figure 4. Although the PGV/PGA ratio of a waveform 
(a)

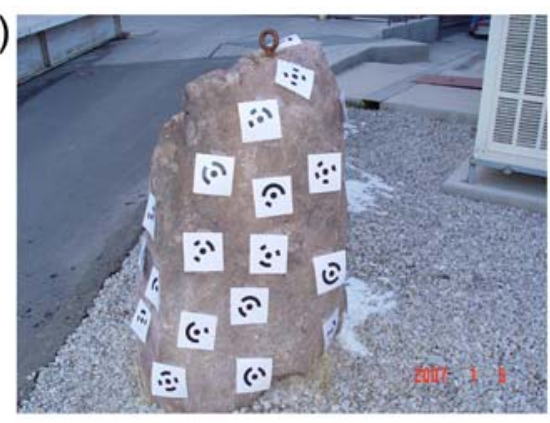

(b)

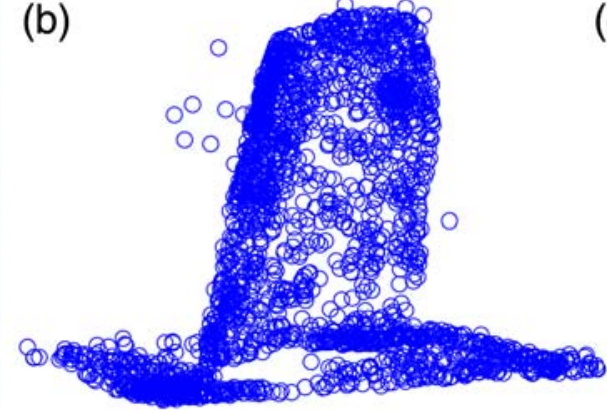

(c)

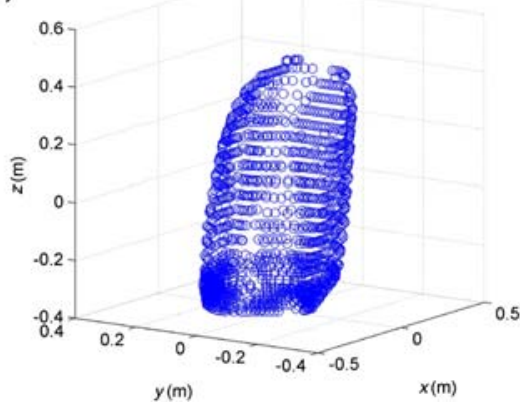

Figure 3. (a) An image of the rock K of Purvance, Anooshehpoor, and Brune (2008) (courtesy: Matt Purvance); rock K is $~ 1 \mathrm{~m}$ tall and $0.4 \mathrm{~m}$ wide, (b) the point cloud obtained by combining the multidirectional images of rock $\mathrm{K}$ using Insight3D, and (c) 3D model of rock $\mathrm{K}$ created from the point cloud. The color version of this figure is available only in the electronic edition.

remains unchanged under linear scaling, it does change when a high-pass Butterworth filter is applied. Hence, the PGV/ PGA obtained for a PGA level of $9.81 \mathrm{~m} / \mathrm{s}^{2}$ might not be the same as that obtained at a PGA level of $0.981 \mathrm{~m} / \mathrm{s}^{2}$. Therefore, the PGV/PGA averaged over all PGA levels for each waveform is used in developing Figure 4.

Here, the 3D model of the rock is analyzed using the rigid-body dynamics algorithm. The pedestal is taken to be a flat horizontal surface, as in the experimental setup. The no-slip boundary condition is enforced through the use of a high value of 2.0 for both static and kinetic friction coefficients between the rock and the pedestal. The rock model is analyzed under the same set of scaled ground-motion waveforms, with the PGD limited to $0.3 \mathrm{~m}$ using a high-pass Butterworth filter. The smallest PGA at which the rock model topples under each scaled waveform is indicated by the filled circles in Figure 4. The results from the rigid-body dynamics algorithm agree well with those from experiments, with the differences in the minimum toppling PGA being less than $0.1 \mathrm{~m} / \mathrm{s}^{2}$ for most waveforms. The only waveform for which the mismatch exceeds $0.1 \mathrm{~m} / \mathrm{s}^{2}$ is the sine wave $(\mathrm{PGV} / \mathrm{PGA}=0.09)$, which has a short duration of $0.5 \mathrm{~s}$. One possible reason for this mismatch may be that the rock experienced sliding coupled with rocking in the experiment. In another shake-table experiment on a different rock, sliding was indeed observed at lower values of PGV/PGA, resulting in higher toppling accelerations. It is difficult to judge from the shake-table experiment videos whether this rock experienced sliding at lower PGV/PGA values, because the rock's base is not clearly visible.

To verify the empirical expression that they had developed, Purvance, Anooshehpoor, and Brune (2008) approximated the rock to a $2 \mathrm{D}$ object with two points of contact. First, assuming the extreme points where the rock is initially in contact are the contact points and applying their empirical equation, they estimated the gray region in Figure 4 as the combination of PGA and PGV/PGA for which the toppling probability of the rock is between 0.05 and 0.95 . The rock was observed to be far more fragile in the shake-table tests than was predicted. Second, they used tilt tests to correct for the positions of the two contact points and re-estimated the toppling fragility. They were able to improve the prediction significantly. Unfortunately, most PBRs are located in difficult terrain and inaccessible locations. It is usually not possible to perform tilt tests on them. In the absence of tilt tests, our algorithm should be preferred over the empirical equation. Also, our approach is nondestructive, whereas tilt tests may not be, because the contact interface between the rock and pedestal, which is disturbed during the tilt test, might not return to the pretilt test state. It is important to note here that the validation exercise presented in this section is based on shake-table experiments conducted on one rock under 10 ground excitations. This validation exercise could be made more robust in the future with the availability of more experimental data.

\section{Critical Toppling Intensity of the Echo Cliffs PBR}

Real world PBRs are quite unlike the laboratory-tested regularly shaped rock $\mathrm{K}$ sitting on a flat horizontal surface. The Echo Cliff PBR is a case in point. It is asymmetric, resting at the edge of a cliff on a downsloping pedestal (with a gradient of about $5^{\circ}$ ) (Fig. 2b), with an overhang of about $4 \mathrm{~m}$ (Fig. 5). Both the gradient and the overhang are oriented at a counterclockwise (CCW) angle of $\sim 135^{\circ}$ to the $\mathrm{x}$ axis. As a consequence, the rock may be particularly vulnerable to sliding, rocking, or coupled rocking-sliding along this direction, with gravity aiding the earthquake excitation in toppling the rock. Of course, given the complex asymmetric geometry of the rock-pedestal system, its dynamic response may be sensitive to the directionality of ground motion as well. Note that adhesion between the PBR and its pedestal, if present, is not modeled in this analysis.

To better estimate the critical toppling intensity of the $\mathrm{PBR}$, it is important to understand the roles played by the friction coefficient between PBR and its pedestal and various ground-motion parameters, such as directionality, PGA, PGV, and duration on the response of the PBR.

\section{Effect of Ground Excitation Direction}

To isolate the effect of the direction of ground excitation, the static and kinetic coefficients of friction between the rock 


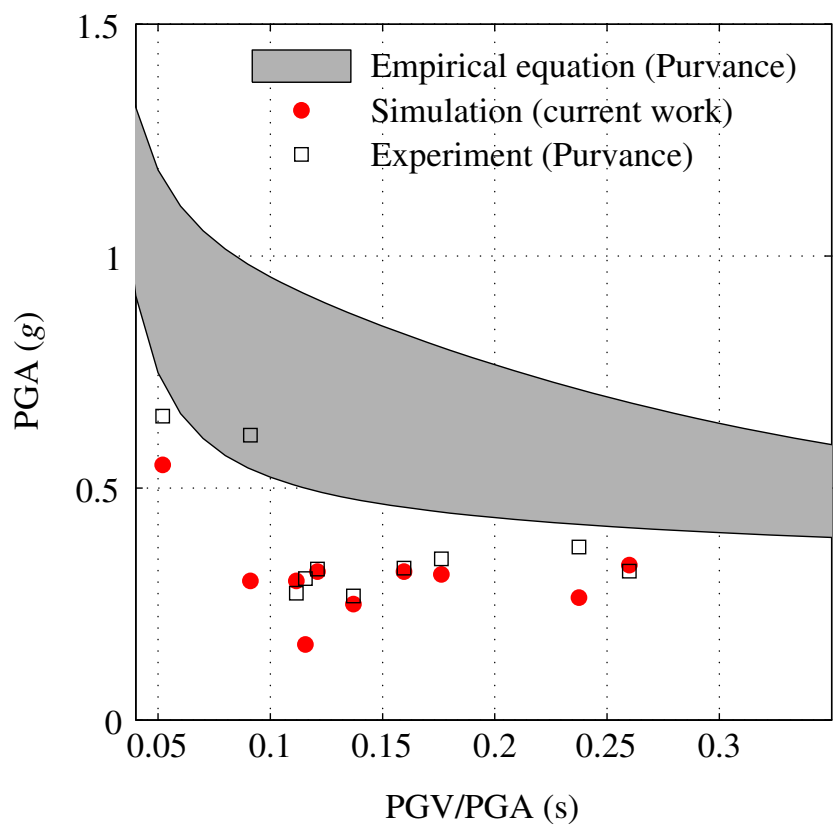

Figure 4. The minimum peak ground acceleration (PGA) required for Purvance et al.'s rock K to topple under scaled versions of 10 ground-motion waveforms characterized by their peak ground velocity (PGV)/PGA (squares, experiment [Purvance, Anooshehpoor, and Brune, 2008]; circles, rigid-body dynamics simulation). The gray region is the combination of PGA and PGV/PGA for which the toppling probability of the rock is between 0.05 and 0.95 from Purvance et al.'s empirical equation (Purvance, Anooshehpoor, and Brune, 2008) that approximates the rock as a 2D object with two points of contact. Because the complex contact interface and the $3 \mathrm{D}$ response of the rock do not factor into the empirical equation, it predicts the rock to be much more stable than the shake-table experiments. This figure has been adapted with permission from Purvance, Anooshehpoor, and Brune (2008). The color version of this figure is available only in the electronic edition.

and its pedestal are set to 1.0 (the upper limit of the range of friction coefficients seen in rocks). With friction coefficients being so high, the rock may be expected to experience rocking predominantly with little or no sliding under ground excitation. The U.S. Geological Survey (USGS) seismic-hazard deaggregation for the Echo Cliff PBR site shows the hazard at this site to be dominated by earthquakes with magnitude greater than 6 and originating close (less than $20 \mathrm{~km}$ ) to the site (E) Fig. S3). However, not many near-field earthquake records exist. So, we estimate the toppling probability of the Echo Cliffs PBR as a function of ground-motion parameters by subjecting it to an ensemble of 140 records from worldwide earthquakes with magnitudes greater than 6 and source-to-site distances less than $100 \mathrm{~km}$ (see Purvance et al., 2012, for the complete list of earthquakes). The earthquake records have been downloaded from the Pacific Earthquake Engineering Research (PEER) Center ground-motion database (Ancheta et al., unpublished manuscript, 2013, see Data and Resources).

The records are first normalized such that the maximum magnitude of the horizontal acceleration vector (horizontal vector PGA) of the ground motion is $1 \mathrm{~m} / \mathrm{s}^{2}$. The normalized

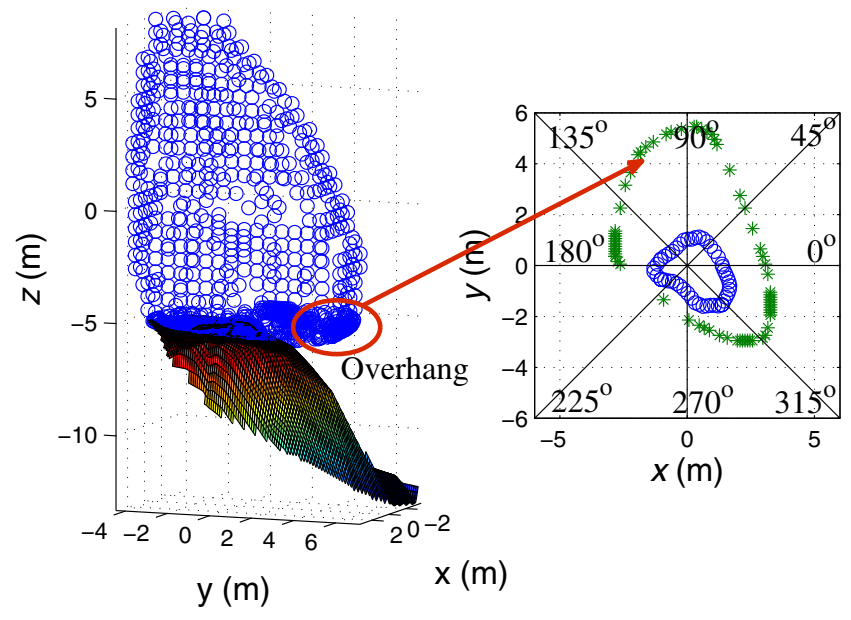

Figure 5. 3D model of the rock and the pedestal. (right) Plan view of the initial contact interface (circles) and the widest part of the rock's base (asterisks) are presented. The overhanging part of the rock's base is located around $135^{\circ}$ counterclockwise (CCW) from the $\mathrm{x}$ axis. The color version of this figure is available only in the electronic edition.

records are scaled to yield records with PGA varying from 1 to $19 \mathrm{~m} / \mathrm{s}^{2}$ in steps of $1 \mathrm{~m} / \mathrm{s}^{2}$. To study the effect of groundmotion directionality, three-component acceleration histories are applied to the pedestal, with the stronger of the two recorded horizontal components (determined using the component PGA), henceforth referred to as strong horizontal component, oriented alternately in eight different directions, namely at $0^{\circ}, 45^{\circ}, 90^{\circ}, 135^{\circ}, 180^{\circ}, 225^{\circ}, 270^{\circ}$, and $315^{\circ} \mathrm{CCW}$ to the $\mathrm{x}$ axis. Note that the pedestal accelerating in the $0^{\circ}$ direction will invoke the rock to respond in the opposite direction, that is, at $180^{\circ}$. The rock-pedestal system is analyzed using our rigid-body dynamics algorithm under the 2660 PGA-scaled earthquake records in each of the eight directions. The direction in which the horizontal vector PGA occurs can differ from the direction of the strong horizontal component. Therefore, the 2660 PGA-scaled earthquakes in the eight directions are binned into eight bins based on the direction of their horizontal vector PGA. All the ground motions having horizontal vector PGA oriented between $-22.5^{\circ}$ and $22.5^{\circ} \mathrm{CCW}$ from the $\mathrm{x}$ axis are in the first bin. The second bin consists of ground motions with horizontal vector PGA oriented between $22.5^{\circ}$ and $67.5^{\circ} \mathrm{CCW}$ from the $\mathrm{x}$ axis, and so on. Each of these eight bins contain 2660 PGA-scaled earthquake records (140 earthquakes $\times 19$ scaling factors).

The toppling probability of the Echo Cliffs PBR as a function of PGA and PGV/PGA is shown in Figure 6 for the fourth bin and eighth bin, in which the horizontal vector PGA is oriented between $112.5^{\circ}$ and $157.5^{\circ}$ and between $292.5^{\circ}$ and $337.5^{\circ} \mathrm{CCW}$ from the $\mathrm{x}$ axis, respectively. The figures corresponding to all eight bins are included in (E) Figure S4. These plots are developed by binning the 140 scaled records at each PGA level into PGV/PGA bins of $0.05 \mathrm{~s}$ width. The toppling probability in each bin at each PGA level is the fraction of records (in that bin and that PGA level) that 

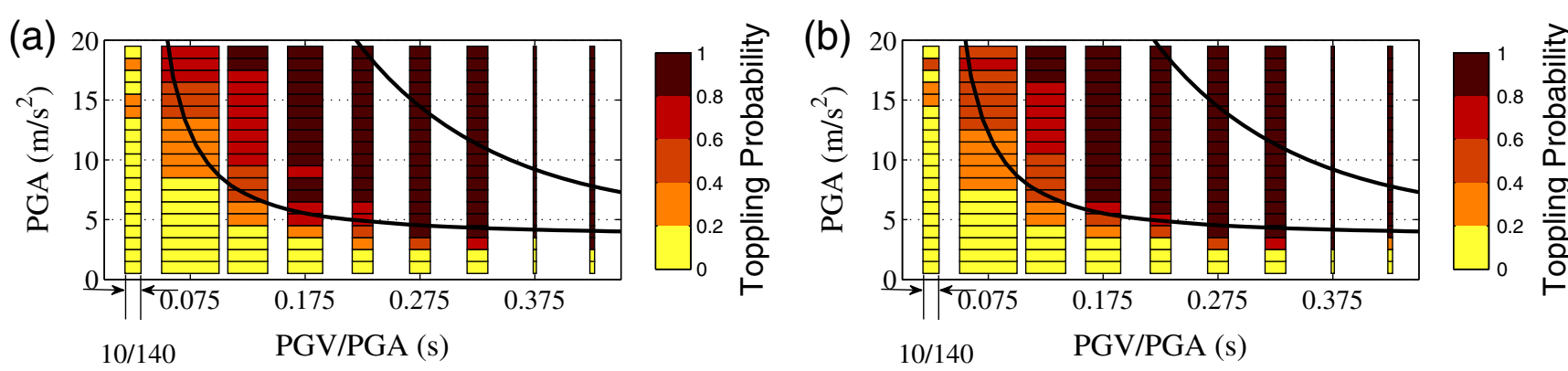

Figure 6. Toppling probability of the Echo Cliffs PBR as a function of PGA and PGV/PGA under three-component pedestal excitation with the horizontal vector PGA oriented between (a) $112.5^{\circ}-157.5^{\circ}$ (fourth bin) and (b) $292.5^{\circ}-337.5^{\circ}$ (eighth bin) CCW to the $\mathrm{x}$ axis obtained using our rigid-body dynamics algorithm. The upper and lower black lines, predicted by the empirical relation of Purvance, Anooshehpoor, and Brune (2008), represent the PGA-PGV/PGA combinations corresponding to rock toppling probabilities of $1 \%$ and $99 \%$, respectively. The color version of this figure is available only in the electronic edition.

topple the model. The thicknesses of the columns along the PGV/PGA axis are proportional to the fraction of earthquake records (out of 140) that are sampled in a given PGV/PGA bin. Regions with thinning columns are regions that are sparsely sampled, and the results there may not be as reliable as the densely sampled regions.

The toppling probability of the rock is very low for PGA less than $3 \mathrm{~m} / \mathrm{s}^{2}$ (Fig. 6). The quasi-static toppling acceleration of the rock, that is, the minimum constant ground acceleration that can topple the rock, varies between 2 and $4 \mathrm{~m} / \mathrm{s}^{2}$, depending on the direction of ground excitation. In a few cases at least, it appears that the rock topples at PGAs smaller than the quasi-static toppling acceleration. For example, if we were to force the rock to topple in the $315^{\circ} \mathrm{CCW}$ direction, that is, directly opposing the gradient of the pedestal, the quasi-static toppling acceleration to be applied in the $135^{\circ}$ direction would have to be $3.65 \mathrm{~m} / \mathrm{s}^{2}$. Yet, several ground-motion records with PGAs around $2.5 \mathrm{~m} / \mathrm{s}^{2}$ with horizontal vector PGA oriented between $112.5^{\circ}$ and $157.5^{\circ}$ appear to topple the rock (Fig. 6a).

This may be attributed to the absence of strong directionality in the ground motion, causing rocking to initiate in other, perhaps more vulnerable, directions. In fact, in 65 (out of 140) earthquake records, the magnitude of acceleration is greater than $0.9 \mathrm{PGA}$ in at least one other direction that is distinctly different (more than $22.5^{\circ}$ ) from the horizontal vector PGA direction. Alternately (or in concert with directions of high accelerations), rocking may initiate in directions in which the rock may have a substantially lower quasi-static toppling acceleration.

The absence of directionality in almost half of the ground-motion records results in little differences in the toppling fragility maps for the eight different bins. Adding to that is the extra vulnerability of the rock in the overhang/ pedestal-downsloping direction $\left(135^{\circ} \mathrm{CCW}\right.$ to the $\mathrm{x}$ axis), in which gravity aids the earthquake excitation in toppling the rock. In $\sim 60 \%$ of the 21,280 cases (140 records $\times 19$ scaling factors $\times 8$ orientations), the rock topples between $122.5^{\circ}$ and $157.5^{\circ}$. Rocking could be initiated in any direction, but the rock finds it easiest to topple in the vicinity of the $135^{\circ} \mathrm{CCW}$ direction, thanks to the presence of the gradient and the overhang.

The PGA required to topple the rock decreases with increase in PGV/PGA (Fig. 6). Purvance, Anooshehpoor, and Brune (2008) demonstrated that PGV/PGA correlates with the duration of the predominant acceleration pulse. It follows, therefore, that as the duration of the acceleration pulse increases, the amplitude required to topple the rock decreases. To further compare the results from our simulation against those obtained from the empirical relation derived by Purvance, Anooshehpoor, and Brune (2008), we approximate the rock to a $2 \mathrm{D}$ cross section balanced on a plane at two contact points (Fig. 7a). These contact points are estimated from the intersection of the direction of excitation with the initial contact interface (Fig. 7b). The input to the empirical equation are the mass of the rock $(m)$, distance of the two contact points from the center of mass $\left(R_{1}\right.$ and $\left.R_{2}\right)$, and the mass moment of inertia (I) of the rock about the center of mass in the direction perpendicular to the ground excitation. The mass and mass moment of inertia are taken from the 3D rock model.

The black lines in Figure 6a,b are the predictions by the empirical relation of Purvance, Anooshehpoor, and Brune (2008). The probability is 0.99 that PGA-PGV/PGA combinations above the upper line would topple the Echo Cliffs PBR, whereas the probability is 0.01 that PGA-PGV/PGA combinations below the lower line would topple the rock. The empirical equation is able to predict the PGA-PGV/ PGA combinations required for lower toppling probabilities well, but fails to accurately predict the PGA-PGV/PGA combinations required for higher toppling probabilities. In particular, the toppling probability is significantly underpredicted for ground excitation oriented at $135^{\circ}$ and $315^{\circ} \mathrm{CCW}$ to the $\mathrm{x}$ axis (Fig. 6), the axis along which the pedestal gradient and the rock overhang are present. The errors of prediction by the empirical equation may be attributed to the rock's motion being constrained to the $2 \mathrm{D}$ plane in the direction of strong ground excitation. That this is not the case for this rock may be seen from an analysis of the rock subjected to a simple idealized sawtooth velocity pulse with 

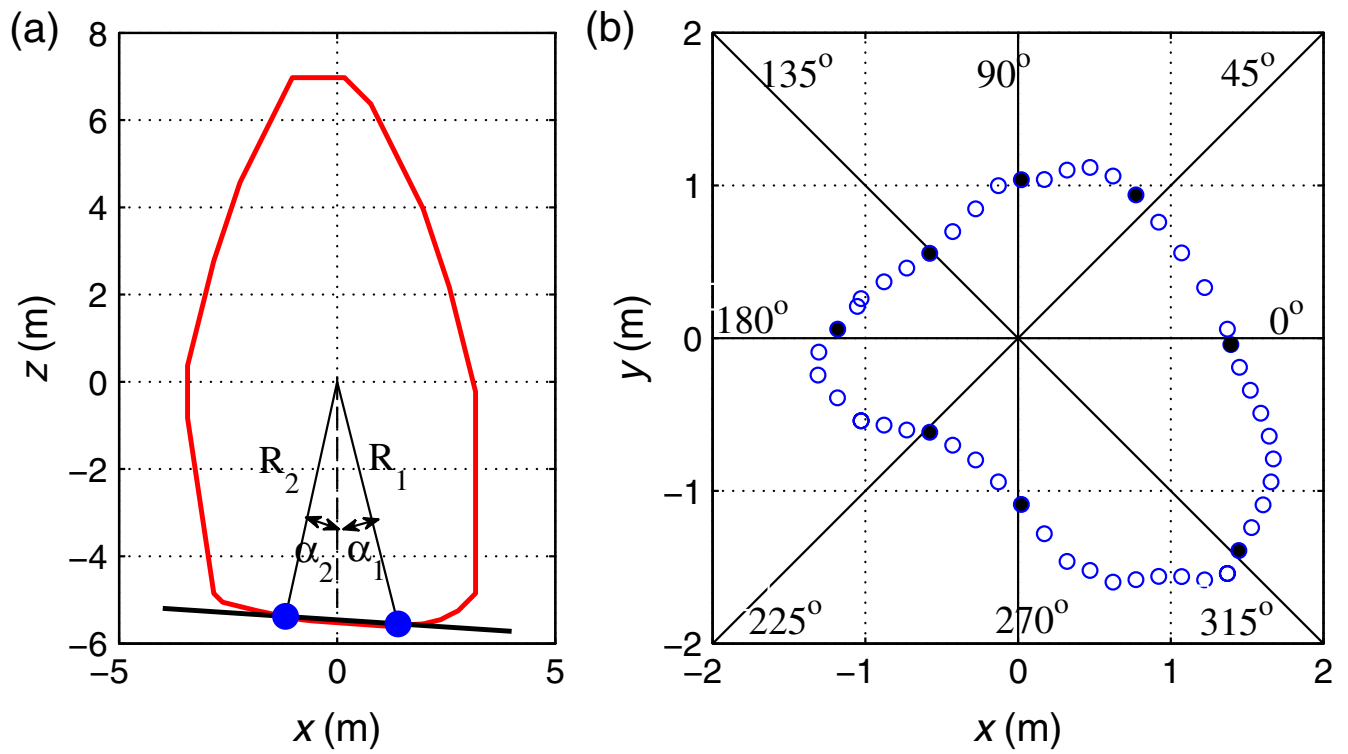

Figure 7. (a) 2D approximation of the rock-pedestal system for excitation applied in the $X$ direction and (b) contact points (filled circles) for the 2D model of the rock in different directions of excitation. The open circles indicate the initial contact interface between the rock and the pedestal. These contact points are estimated from the intersection of the direction of excitation with the initial contact interface. The color version of this figure is available only in the electronic edition.
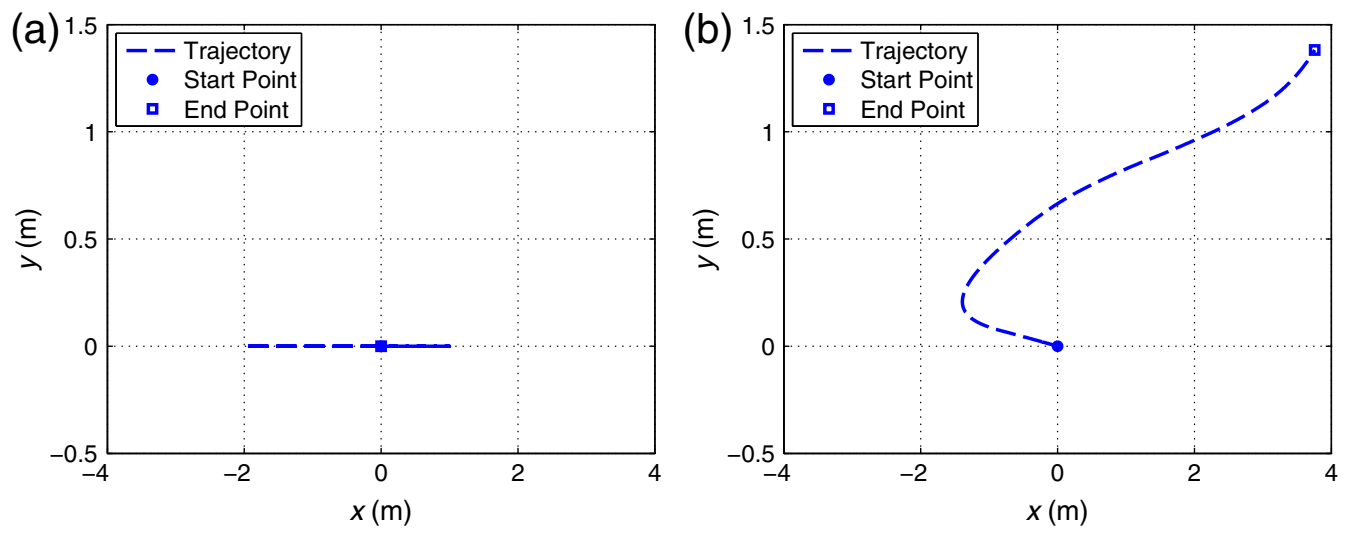

Figure 8. 2D and 3D rock models subjected to 1 -cycle idealized sawtooth waveform excitation with $T=3.5 \mathrm{~s}$ and PGV $=5 \mathrm{~m} / \mathrm{s}$ applied at $0^{\circ}$ to the $\mathrm{x}$ axis. Trajectories of the center of mass projected on to the $X-Y$ (horizontal) plane for (a) 2D rock model with 2-point contact (rock does not topple) and (b) 3D rock-pedestal model (rock topples). The color version of this figure is available only in the electronic edition.

PGV of $5 \mathrm{~m} / \mathrm{s}$ and a time period $T$ of $3.5 \mathrm{~s}$ applied at $0^{\circ}$ to the $\mathrm{x}$ axis (Fig. 8).

\section{Effect of Ground-Motion Intensity Measures}

The sensitivity of the toppling probability of the rock model to other ground-motion parameters is explored by plotting the toppling probability on the PGA-PGV (Fig. 9) plane. Only the results corresponding to the horizontal vector PGA being oriented at $292.5^{\circ}$ and $337.5^{\circ} \mathrm{CCW}$ to the $\mathrm{x}$ axis are presented here. The results corresponding to the other directions are qualitatively similar. This figure is developed by binning the 140 -scaled records at each PGA level into PGV bins of $0.25 \mathrm{~m} / \mathrm{s}$ width. The toppling probability in each bin at each PGA level is the fraction of records (in that bin and that PGA level) that topple the rock model. It should be noted that the PGA-PGV domain in Figure 9 is not uniformly sampled by the 2660-scaled records. The thickness of the column at each PGA level in a given PGV bin is proportional to the fraction of points (out of 140) being sampled in that bin. It can be seen from the figure that the toppling probability is quite low for PGA and PGV below $3 \mathrm{~m} / \mathrm{s}^{2}$ and $0.75 \mathrm{~m} / \mathrm{s}$, respectively. A small fraction of records with PGA in the $4-7 \mathrm{~m} / \mathrm{s}^{2}$ range and $\mathrm{PGV}$ in the $0.25-0.5 \mathrm{~m} / \mathrm{s}$ range are able to topple the rock model (Fig. 9). Also, the PGV required to topple the rock increases gradually with PGA (follow the bins with toppling probability in the 0.8-1.0 range in Fig. 9). 


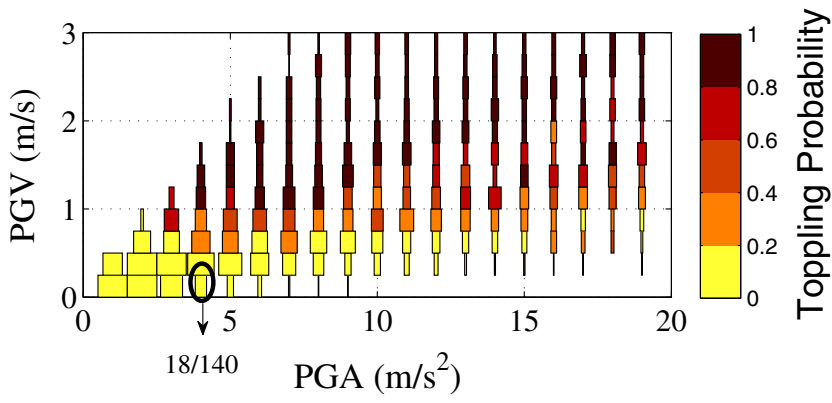

Figure 9. Toppling probability of the Echo Cliffs PBR as a function of PGV and PGA. Each column in the figure contains the results from 140 earthquake records scaled to a specific PGA level. The varying thicknesses of the column are proportional to the fraction of earthquakes (out of 140) being sampled in a given PGV bin. The color version of this figure is available only in the electronic edition.

To further explore the relative importance of PGV and PGA in toppling the rock, the toppling probability of the rock is plotted on the PGV-duration (Fig. 10a) and PGA-duration planes (Fig. 10b). The duration of the strong shaking is defined as the length of the record (in seconds) within which $90 \%$ of the seismic energy is contained. Here, we use Anderson's energy integral formulation (Anderson, 2004) to determine the duration of the 140 earthquake records. In this method, the square of the velocity time history is integrated to arrive at the energy of the record. Figure 10a is developed by dividing the scaled earthquake records with PGV less than $3 \mathrm{~m} / \mathrm{s}$ into bins of width $0.25 \mathrm{~m}$ in PGV and $5 \mathrm{~s}$ in duration. Figure 10b is developed similar to Figure 6 by dividing the 140 earthquake records at each PGA level into bins of width $5 \mathrm{~s}$ in duration. Figure 10a shows that the PGV required to topple the rock model is more or less independent of the duration of the earthquake. However, the PGA required to topple the rock model decreases more or less uniformly with duration. In other words, a short duration of strong acceleration is unlikely to result in a large enough velocity pulse. These figures suggest that above a PGA limit $\left(3 \mathrm{~m} / \mathrm{s}^{2}\right.$ in this case), the toppling probability of the rock is governed by PGV that is a measure of the kinetic energy imparted by the ground motion.

\section{Effect of Friction Coefficient}

Next, we vary the rock-pedestal friction coefficients and compare the toppling probabilities of the rock. For this analysis, we orient the horizontal vector PGA of the ground motion between $292.5^{\circ}$ and $337.5^{\circ} \mathrm{CCW}$ to the $\mathrm{x}$ axis to get the base of the rock moving in its most vulnerable direction (at $135^{\circ}$ $\mathrm{CCW}$ to the $\mathrm{x}$ axis along the pedestal gradient and rock overhang). Here, too, we assume the same coefficient for static and kinetic friction. We analyze the rock under the 2660 -scaled records for friction coefficients $(\mu)$ of 0.6 and 0.8 and compare the results with that obtained earlier for $\mu=1.0$. When the PBR is subjected to earthquake excitation, it can slide, rock, or exhibit sliding coupled with rocking. For a constant ground acceleration, the response mode of the rock shifts from pure sliding to sliding coupled with rocking, and then to pure rocking with increase in the coefficient of friction. For a rigid rectangular object placed on a rigid horizontal ground, Shenton (1996) obtained the relation between the constant horizontal ground acceleration and the coefficient of friction required to initiate rocking, sliding, and coupled rocking-sliding of the object. He observed that for a ground excitation amplitude greater than the quasi-static toppling acceleration of the object, it can undergo pure sliding only for friction coefficients below its width-to-height ratio. This observation, when applied to the $2 \mathrm{D}$ cross section of the PBR at $135^{\circ}$ (similar to Fig. 7a), shows that the rock can undergo pure sliding only if $\mu$ is less than 0.15 . Though the gradual pedestal gradient is not considered in this simple calculation, it can be shown that the transition from sliding to sliding coupled with rocking will occur at even lower values of friction coefficient when the gradient in contact interface is included. Therefore, for the range of friction coefficients observed in rocks (0.6-1.0), we expect the PBR will exhibit either pure rocking or sliding coupled with rocking under earthquake excitation.

If the rock were to exhibit only sliding, the relative displacement of the contact points with respect to the pedestal can be used as a measure of the sliding displacement. However, rocking in 3D can also affect the relative displacements of the contact points with respect to the pedestal. Therefore, the effect of sliding cannot be isolated when the rock exhibits sliding coupled with rocking. Moreover, the alignment of the preferred toppling direction (direction of the overhang) of the rock with the preferred sliding direction (gradient of the contact interface) makes it harder to judge the contribution of sliding to the toppling of the rock model on a case-by-case basis. Nonetheless, comparison of the toppling probability of the rock model in the PGV-PGA plane for different friction coefficients provides qualitative insights into the effect of sliding on the toppling of the rock model (Fig. 11a,b).

The toppling probability from each cell of Figure 9 for $\mu=1.0$ is compared against that for the same cell in the corresponding figures developed for $\mu=0.6$ (Fig. 11a) and for $\mu=0.8$ (Fig. 11b). If the response of the rock was independent of the coefficient of friction, all points would lie on the dashed black diagonal line. The following observations can be made: (1) friction does play a role in the response of the rock; (2) a lower friction coefficient results in higher probability of toppling (most points in Fig. 11a and a large majority of the points in Fig. 11b lie above the dashed diagonal line); sliding makes the rock more susceptible to toppling over the cliff; (3) in general, the toppling probabilities for $\mu=0.6$ and $\mu=0.8$ are within \pm 0.3 of those for $\mu=1.0$ (indicated by the solid black bounding lines in these figures).

\section{Conclusions}

In this article, we presented the methodology used to create 3D models of PBRs and their supporting pedestals, as well as details of the rock-pedestal interfaces (refer to 

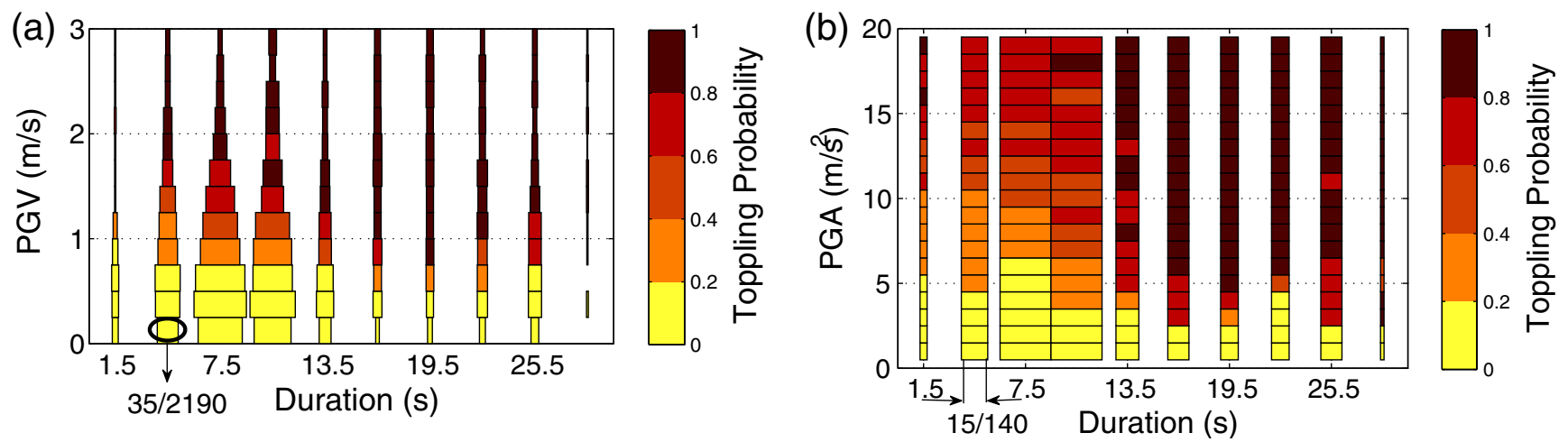

Figure 10. Toppling probability of the Echo Cliffs PBR as a function of (a) PGV and duration, and (b) PGA and duration. 2190 out of the 2660 scaled earthquake records with PGV less than $3 \mathrm{~m} / \mathrm{s}$ and duration less than $30 \mathrm{~s}$ are used for (a). The 2190 earthquakes are divided into bins of width $0.25 \mathrm{~m} / \mathrm{s}$ in PGV and $5 \mathrm{~s}$ in duration. The varying thicknesses of the column are proportional to the fraction of earthquakes (out of 2190) that are sampled in a given PGV and duration bin. Each column in (b) contains 140 earthquake records scaled to a specific PGA level. The varying thicknesses of the column are proportional to the fraction of earthquakes (out of 140) being sampled in a given duration bin. The color version of this figure is available only in the electronic edition.
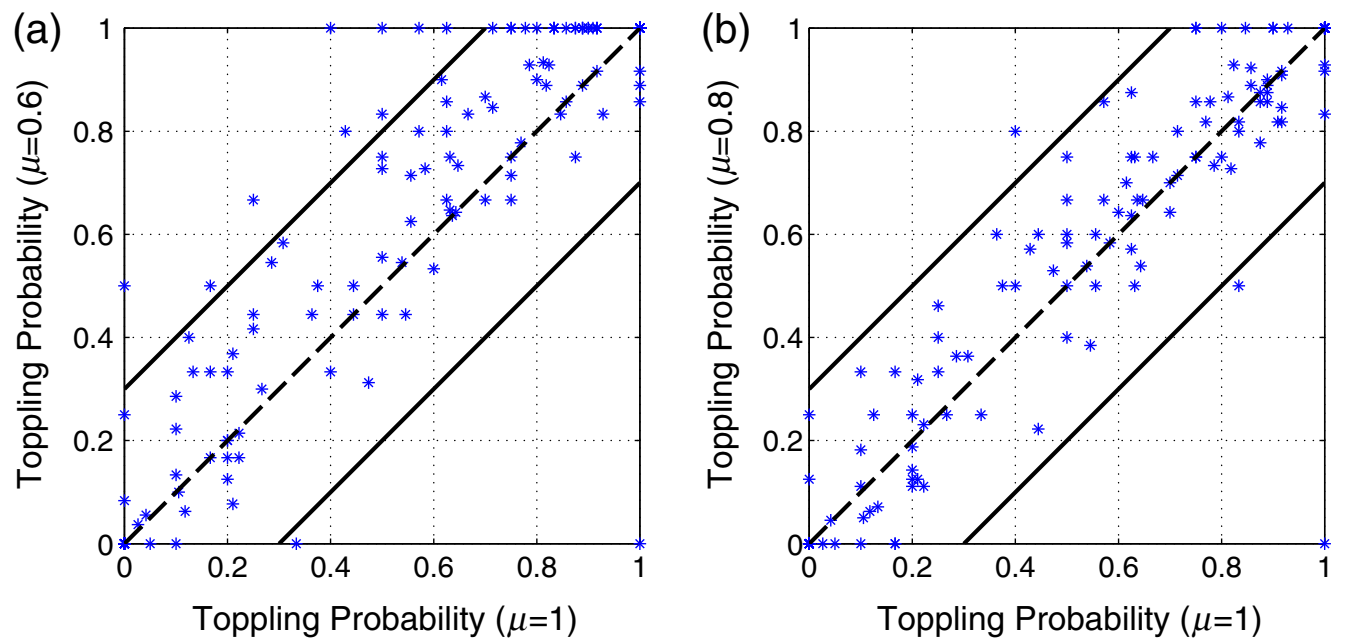

Figure 11. Comparison of toppling probability of the Echo Cliffs PBR taken from the PGV-PGA plane for (a) $\mu=0.6$ and (b) $\mu=0.8$ against that for $\mu=1.0$. Each data point is a direct comparison between the toppling probability of a PGV bin at a given PGA level for $\mu=0.6$ and $\mu=0.8$ against $\mu=1.0$. Most of the data points are contained within the solid black lines, which indicate that the toppling probability for $\mu=0.6$ and $\mu=0.8$ are within 0.3 of that for $\mu=1.0$. Additionally, the asymmetric distribution of data points about the center line indicates that lower friction coefficients result in higher toppling probabilities. The color version of this figure is available only in the electronic edition.

the (E) electronic supplement for details) and to analyze them under three-component earthquake ground excitation. The accuracy of the rigid-body dynamics algorithm used to analyze the rock models is first established through comparisons against shake-table tests on rocks. Fragility maps are then developed for the Echo Cliffs PBR by analyzing the rock under ground motions from 140 earthquakes.

The toppling probability of the Echo Cliffs PBR is quite low (less than 0.2) for PGA and PGV below $3 \mathrm{~m} / \mathrm{s}^{2}$ and $0.75 \mathrm{~m} / \mathrm{s}$, respectively. This suggests that the PGA and PGV at this location from earthquakes that originated on nearby faults during the age of the PBR are most probably less than $3 \mathrm{~m} / \mathrm{s}^{2}$ and $0.75 \mathrm{~m} / \mathrm{s}$, respectively. The PGA and PGV recorded near the Echo Cliffs PBR location (CGS station
25,148 located $12 \mathrm{~km}$ west of the Echo Cliffs PBR) during the 1994 Northridge earthquake were $\sim 2 \mathrm{~m} / \mathrm{s}^{2}$ and $0.12 \mathrm{~m} / \mathrm{s}$, respectively, both smaller than the values listed above. The combined effect of the asymmetric geometry of the Echo Cliffs PBR, the presence of the rock on an inclined rockpedestal interface, and the 3D nature of the ground motion cause this large rock to topple at small ground-motion intensities. A 2D analysis using the empirical relation of Purvance, Anooshehpoor, and Brune (2008) for the same rock predicts it to be more stable (requiring higher PGA and PGV to topple the rock) because the complex rock-pedestal interface and 3D effect of the rock geometry and the ground excitation are not considered in their approach (Fig. 6). Our analyses demonstrate that the $\mathrm{PGV}$ required to topple the 
rock is more or less independent of the duration of ground excitation, whereas the PGA required to topple the rock model decreases with increase in ground-motion duration. These results suggest that although a minimum PGA is required to initiate rocking response of the PBR, the toppling of the rock is dictated by the PGV of the ground-motion record.

The effect of the directionality of ground excitation and rock-pedestal interface friction coefficient on the toppling probability of the Echo Cliffs PBR was also explored. The toppling probabilities and the direction in which the Echo Cliffs PBR toppled were more or less independent of the direction in which the horizontal vector PGA of the ground motion was applied for two reasons: (1) half of the records selected for the study did not exhibit strong directionality and (2) the pedestal on which the rock rests has a downsloping gradient, and a fourth of the base of the rock along the same direction extends beyond the edge of the cliff as an overhang. A lower friction coefficient results in a systematically higher probability of toppling. However, the bulk of the toppling probabilities for $\mu=0.6$ and $\mu=0.8$ are still within \pm 0.3 of those for $\mu=1.0$.

The fragility maps generated using this methodology along with the age of the PBR can be used with the methodology presented in Purvance, Brune et al. (2008) and Baker et al. (2013) to obtain constraints on unexceeded ground motion at a location during the age of the PBR. This has not been attempted for the Echo Cliffs PBR, because the age of this PBR is unknown in quantitative terms. These fragility maps can also be used to conduct reality checks on scenario groundmotion simulations by verifying that the ground motions at the location of the PBR do not topple the PBR. This study can potentially be extended in the future to create accurate fragility maps for the many rocks cataloged by Brune et al. (2006) to obtain region-wide seismic-hazard assessment for southern California and reality checks on scenario earthquake groundmotion simulations, such as the suite of scenarios that are being developed by Given et al. (2014) for testing the ShakeAlert earthquake early warning system.

\section{Data and Resources}

The data for rock $\mathrm{K}$ were provided by Matthew Purvance. The images for rock $\mathrm{K}$ were stitched together using Insight3D accessed using http://insight3d.sourceforge.net/ (last accessed in October 2014). The earthquake records used in this study were downloaded from the Pacific Earthquake Engineering Research (PEER) Center strong ground motion database (last accessed in August 2014). The rigid-body dynamics algorithm used for analyzing precariously balanced rocks (PBRs) is from chapter 2 of Veeraraghavan (2015). The unpublished manuscript by T. D. Ancheta, R. B. Darragh, J. P. Stewart, E. Seyhan, W. J. Silva, B. S. J. Chiou, K. E. Wooddell, R.W. Graves, A. R. Kottke, D. M. Boore, et al. (2013) is "PEER NGA-West2 database."

\section{Acknowledgments}

We thank James Brune, Richard Brune, Glenn Biasi, and Matthew Purvance for the results from the shake-table experiments and for sharing their insights and experiences with precariously balanced rocks (PBRs). We would also like to thank David Phillips of UNAVCO for supporting laser scanning of the Echo Cliffs PBR, as well as the field crew that included D. Haddad, D. Rood, A. Limaye, W. Amidon, D. Lynch, and E. Pounders, and also G. Bawden and S. Bond who helped process the data. In addition, we thank Robert Graves, Thomas Hanks, and Patricia McCrory of U.S. Geological Survey (USGS), Jack Baker, and an anonymous reviewer for providing reviews of earlier versions of this article. This research project has been supported by the National Science Foundation (NSF Award EAR-1247029), the USGS, and the Southern California Earthquake Center (SCEC). Any use of trade, firm, or product names is for descriptive purposes only and does not imply endorsement by the U.S. Government.

\section{References}

Anderson, J. G. (2004). Quantitative measure of goodness of fit of synthetic seismographs, Proc. of the 13th World Conference on Earthquake Engineering, Vancouver, B.C., Canada, 1-6 August 2004.

Anderson, J. G., G. P. Biasi, and J. N. Brune (2014). Precarious rocks: Providing upper limits on past ground shaking from earthquakes, in Earthquake Hazard, Risk, and Disasters, J. Shroder and M. Wyss (Editors), Elsevier, London, United Kingdom, 377-403.

Andrews, D. J., T. C. Hanks, and J. W. Whitney (2007). Physical limits on ground motion at Yucca Mountain, Bull. Seismol. Soc. Am. 97, no. 6, 1771-1792.

Anooshehpoor, A., J. N. Brune, and Y. Zeng (2004). Methodology for obtaining constraints on ground motion from precariously balanced rocks, Bull. Seismol. Soc. Am. 94, no. 1, 285-303.

Baker, J. W., N. A. Abrahamson, J. W. Whitney, M. P. Board, and T. C. Hanks (2013). Use of fragile geologic structures as indicators of unexceeded ground motions and direct constraints on probabilistic seismic hazard analysis, Bull. Seismol. Soc. Am. 103, 1898-1911.

Bell, J. W., J. N. Brune, T. Liu, M. Zerda, and J. C. Yount (1998). Dating the precariously balanced rocks in seismically active parts of California and Nevada, Geology 26, 495-498.

Brune, J. N. (1996). Precariously balanced rocks and ground motion maps for southern California, Bull. Seismol. Soc. Am. 86, no. 1A, 43-54.

Brune, J. N., and J. W. Whitney (1992). Precariously balanced rocks with rock varnish-Paleoindicators of maximum ground acceleration, Seismol. Res. Lett. 63, no. 1, 21.

Brune, J. N., A. Anooshehpoor, M. D. Purvance, and R. J. Brune (2006). Band of precariously balanced rocks between Elsinore and San Jacinto, California, fault zones: Constraints on ground motion for large earthquakes, Geology 34, no. 3, 137-140.

Byerlee, J. (1978). Friction of rocks, Pure Appl. Geophys. 116, no. 4, 615-628.

Given, D. D., E. S. Cochran, H. Heaton, E. Hauksson, R. Allen, P. Hellweg, J. Vidale, and P. Bodin (2014). Technical implementation plan for the ShakeAlert production system-An earthquake early warning system for the west coast of the United States, U.S. Geol. Surv. Open-File Rept. 2014-1095.

Hanks, T. C., N. A. Abrahamson, J. W. Baker, D. M. Boore, M. P. Board, J. N. Brune, C. A. Cornell, and J. W. Whitney (2013). Extreme ground motions and Yucca Mountain, U.S. Geol. Surv. Open-File Rept. 20131245.

Housner, G. W. (1963). The behavior of inverted pendulum structures during earthquakes, Bull. Seismol. Soc. Am. 53, no. 2, 403-417.

Hudnut, K. W., W. Amidon, G. Bawden, J. Brune, S. Bond, R. Graves, D. E. Haddad, A. Limaye, D. K. Lynch, D. A. Phillips, et al. (2009). The Echo Cliffs precariously balanced rock: Discovery and terrestrial laser scanning, presented at the SCEC 2009 Annual Meeting, pages Poster 1-044, Southern California Earthquake Center. 
Ikegami, R., and F. Kishinouye (1947). A study on the overturning of rectangular columns in the case of the Nankai Earthquake on December 21, 1946, Bull. Earthq. Res. Inst. 25, 49-55.

Ikegami, R., and F. Kishinouye (1950). The acceleration of earthquake motion deduced from overturning of the gravestones in case of the Imaichi Earthquake on December 26, 1949, Bull. Earthq. Res. Inst. 28, 121-128.

Ishiyama, Y. (1982). Motions of rigid bodies and criteria for overturning by earthquake excitations, Earthq. Eng. Struct. Dynam. 10, 635-650.

Kimura, T. R., and K. Iida (1934a). On the rocking of rectangular columns (I), Zisin 6, no. 3, 125-149.

Kimura, T. R., and K. Iida (1934b). On the rocking of rectangular columns (II), Zisin 6, no. 4, 165-212.

Kirkpatrick, P. (1927). Seismic measurements by the overthrow of columns, Bull. Seismol. Soc. Am. 17, no. 2, 95-109.

Linton, D. L. (1955). The problem of tors, Geogr. J. 121, no. 4, 470-487.

Purvance, M., A. Anooshehpoor, and J. N. Brune (2008). Freestanding block overturning fragilities: Numerical simulation and experimental validation, Earthq. Eng. Struct. Dynam. 37, 791-808.

Purvance, M., R. Anooshehpoor, and J. N. Brune (2012). Fragilities for precarious rocks at Yucca Mountain, Nevada, PEER Report 2012/06.

Purvance, M., J. N. Brune, N. A. Abrahamson, and J. G. Anderson (2008) Consistency of precariously balanced rocks with probabilistic seismic hazard estimates in Southern California, Bull. Seismol. Soc. Am. 98, no. 6, 2629-2640.

Shenton, H. W. (1996). Criteria for initiation of slide, rock, and slide-rock rigid-body modes, J. Eng. Mech. 122, 690-693.

Shi, B., A. Anooshehpoor, Y. Zeng, and J. N. Brune (1996). Rocking and overturning of precariously balanced rocks by earthquakes, Bull. Seismol. Soc. Am. 86, 1364-1371.

Stepp, J., I. Wong, J. Whitney, R. Quittemeyer, N. Abrahamson, G. Toro, R. Youngs, K. Coppersmith, J. Savy, and T. Sullivan (2001). Probabilistic seismic hazard analyses for ground motions and fault displacements at Yucca Mountain, Nevada, Earthq. Spectra 17, 113-151.
Taniguchi, T., and T. Miwa (2007). A simple procedure to approximate slip displacement of freestanding rigid body subjected to earthquake motions, Earthq. Eng. Struct. Dynam. 36, 481-501.

Veeraraghavan, S. (2015). Toppling analysis of precariously balanced rocks, $P h$. D. Dissertation, California Institute of Technology, Pasadena, California.

Voyagaki, E., G. Mylonakis, and L. N. Psycharis (2012). Rigid block sliding to idealized acceleration pulses, J. Eng. Mech. 138, 1071-1083.

Voyagaki, E., L. N. Psycharis, and G. Mylonakis (2014). Complex response of a rocking block to a full-cycle pulse, J. Eng. Mech. 140, no. 6, 1071-1083.

Yerkes, R. F., R. H. A. Campbell, and D. L. Turner (1979). Stratigraphic nomenclature of the central Santa Monica Mountains, Los Angeles County, California, with a section on age of the Conejo volcanics, U.S. Geol. Surv. Open-File Rept. 1457E.

Yim, C., A. K. Chopra, and J. Penzien (1980). Rocking response of rigid blocks to earthquakes, Earthq. Eng. Struct. Dynam. 8, 565-587.

Zhang, J., and N. Makris (2001). Rocking response of free-standing blocks under cycloidal pulses, J. Eng. Mech. 127, 473-483.

California Institute of Technology

1200 East California Boulevard

MC 104-44

Pasadena, California 91125

sveerara@caltech.edu

krishnan@caltech.edu

(S.V., S.K.)

U.S. Geological Survey

525535 South Wilson Street

Pasadena, California 91106

hudnut@usgs.gov

(K.W.H.)

Manuscript received 29 May 2016;

Published Online 13 December 2016 